\title{
ARQUEOLOGÍA EXPERIMENTAL: ¿QUIÉN LA PRACTICA, CUÁL ES SU UTILIDAD?
}

\author{
Experimental archeology: who practices it, what is its utility? \\ Roeland Paardekooper ${ }^{1}$ \\ https://doi.org/10.15366/baexuam2020.14.004 \\ (Traducción por Olga Palacios Martínez²)
}

\section{Resumen}

A través de dos encuestas realizada en los años 2010 y 2018, diversas personas que trabajan en la arqueología experimental explicaron su visión de esta ciencia y describieron qué tipo de actividades relacionadas realizan. Se preguntó a universidades, sociedades, freelancers y museos. Diversas actividades adyacentes fueron comentadas, como por ejemplo la arqueo-técnica que es la realización de reconstrucciones y experimentos en vivo. Después de algunas confusiones y ejemplos aclaradores, se comenta el futuro de la arqueología experimental como disciplina para el uso no únicamente científico sino también social.

Este artículo es solamente una pequeña aproximación a discusiones e investigaciones mucho más extensas sobre este campo de investigación. Lara Comis (miembro de EXARC), actualmente está realizando un Doctorado financiado por la IRC en la UCD (IE) explorando la Arqueología Experimental y los museos arqueológicos al aire libre. Su investigación se inició con la presente encuesta, la cual varios miembros de EXARC ya les será familiar, que trata sobre como la arqueología experimental es entendida. Su trabajo está promovido activamente por EXARC.

Este estudio cuenta con una gran cantidad de información recopilada pero, solo ha sido posible publicar una fracción de este material. La mayoría de los artículos publicados aparece solamente en la literatura gris o literatura poco convencional. Por este motivo, EXARC tomó la iniciativa de recopilar esta información a través de su Colección de arqueología experimental, la cual está disponible en experimentalarchaeology.net.

Palabras clave: Arqueología experimental, Europa

\section{Abstract}

The time that experimental archaeology was confined to purely scientific exercises with a clear hypothesis, workflow and outcome is gone. Experimental archaeology is a versatile tool that connects museums, universities, societies and freelancers. If some parts of these cooperative activities are better structured, the added value of experimental archaeology is enormous. This article quotes many experimental archaeologists and their opinion about the profession.

There are several activities, which pop up each time when there is talk about experimental archaeology, like archaeotechnique, making reconstructions and life experiments. While these are valuable activities, they have their own purpose and are different from experimental archaeology per se. But some of the best experimental archaeologists are

\footnotetext{
${ }^{1}$ EXARC, Middelaldercentret, Denmark. ORCID 0000-0003-1678-1158 r.p.paardekooper@exarc.net

2 olgaapalacios@gmail.com
} 
engineers or craftspeople, cooperating with archaeologists. Starting out from the scientific realm, experimental archaeology is an approach to the archaeological record, which starts with good research into the primary sources. This is followed by setting up and testing a hypothesis, an action. This action leaves traces which are then compared with the archaeological record to better understand the hypothesised action from the past. Experimental archaeology has become an important tool to help understand the archaeological past. Thanks to the extensive number of experiments, we are coming closer to understanding how life may have been in the past.

Keywords: Experimental archaeology, Europe

\section{Introducción}

La arqueología experimental es tan antigua como la misma arqueología. Coles describió en el siglo XVI ejemplos como: 'cualquier esfuerzo honesto para entender los artefactos antiguos que trabajan actualmente con ellos' (Coles, 1979, pp. 11 - 12). El objetivo principal era descubrir más sobre el origen de los artefactos: ¿los artefactos fueron hechos por gente o tienen un origen natural? En definiciones más recientes, por ejemplo: 'una subdisciplina de la investigación arqueológica que utiliza un número de métodos diferentes, técnicas, análisis y aproximaciones en el contexto de experimentos imitables controlables para replicar el fenómeno del pasado [desde objetos a sistemas] con la voluntad de generar y avaluar hipótesis que proveen o realzan analogías de la interpretación arqueológica' (Mathieu, 2002) cambiando la atención de una aproximación puramente técnica a avaluar hipótesis a través de la construcción de una comparación práctica e inmersiva con el pasado. No se puede hacer arqueología experimental meramente como un estudio documental. Es muy complicado aprender una técnica antigua en un libro o video puesto que solamente cubren unos pocos aspectos; se tiene que experimentar en la realidad, y esto incluye todos los sentidos, requiere una cierta agilidad para obtener una comprensión del espacio, forma y material.

La arqueología experimental por sí misma no conduce a productos tangibles. Los resultados del proceso es información y conocimiento obtenidos a través de la experiencia. La arqueología experimental es a la vez una aproximación técnica, de ciencia natural, pero también una ciencia social. No es solo la investigación de los artefactos, es la voluntad de descubrir más sobre la gente detrás de estos artefactos.

\section{La arqueología experimental en Europa: ¿Quién y Cuándo?}

EXARC es la organización afiliada a ICOM y trata temas de museos arqueológicos al aire libre, arqueología experimental, tecnología e interpretación antigua (Paardekooper, 2013). Actualmente cuenta con 300 miembros de más de 40 países y ofrece una fuerte cadena de soporte entre artesanos, investigadores, educadores y artistas. EXARC ha preguntado dos veces a sus miembros sobre sus experiencias en la arqueología experimental, en 2010 y en 2018.

\section{Encuesta de 2010}

Las nueve respuestas obtenidas en 2010 incluyeron algunas perspectivas honestas: la gente intenta hacer arqueología experimental, pero somos conscientes de nuestras propias restricciones y limitaciones del método (EXARC, 2010). Es importante remarcar que ocho de las respuestas provenían de organización que sobretodo trabajan con el público (museos y centros al aire libre).

Según Stefani (EXARC 2010), 'está claro que no tenemos un conocimiento completo de nuestro pasado dado que el registro arqueológico está incompleto; es como meterse dentro 
de las mentes de nuestros antepasados y enfrentarse con los mismos problemas que ellos tuvieron que resolver' (EXARC 2010).

'La arqueología experimental es una herramienta practica que te puede ayudar a entender el pasado' Vemming Hansen, Middelaldercentret, Dinamarca (EXARC 2010).

Te puede acercar a cómo pudieron haber sido las cosas en el pasado, pero uno nunca lo sabrá de cierto. Aunque los experimentos deberían ser repetibles, muchas veces es difícil.

'No se puede repetir la construcción de una casa con exactamente las mismas circunstancias una vez tras otra' Frisk, Genesmons Arkeologiska Friluftsmuseum, Suecia (EXARC 2010).

A veces, artefactos y casas se construyen para que se parezcan a los originales (Coles 1979, sobre el primero de las tres fases de construcción) y no están hechos de la manera original. Esto, en parte, es a causa de las regulaciones en la construcción para garantizar la salud y seguridad, pero también porqué este tipo de casas a veces no están destinadas para la arqueología experimental, sino para los museos. Esto no es un problema en la medida que los museos sean honestos sobre este aspecto. Las demostraciones y la educación no son arqueología experimental, pero la experimentación puede ayudar a las actividades en estas dos direcciones.

'Los principios descritos por John Coles en sus dos libros son aún actuales, y puede que su respuesta en la cuestión ‘Cómo se utiliza?' Puede que sea así - no mezclar arqueología experimental con arqueología festival, siempre explicar a los visitantes qué es real y qué no lo es' Piotrowski, Muzeum Archeologiczne w Biskupinie, Polonia (EXARC 2010).

Experiencias personales, momentos eureka si quieres, suceden todo el tiempo en museos arqueológicos al aire libre.

'Los botes de madera son siempre mejores si están hechos con la base plana, un horno de vidrio funciona mejor si es circular (en lugar de oval como sería el de hornear pan), el aceite vegetal es suficiente para forjar acero, y realmente con solo paja se puede convertir la arcilla en una simple versión de hormigón acorazado' Kock, Geschichserlebnisraum Lübeck, Alemania (EXARC 2010).

Estas experiencias son similares a las que se pueden encontrar por parte de estudiantes de arqueología teniendo la misma experiencia en replicando cultura material arqueológica.

La perspectiva obtenida en la entrevista de 2010 fue que la arqueología experimental era un método puramente científico, el cual debe ser tratado de esta manera. No obstante, aún en 2010, demostraciones y en la educación estaban marcados por temas adyacentes, experiencias personales eran consideradas demasiadas veces como elementos valiosos.

\section{Entrevista 2018}

En 2018, EXARC pudo profundizar en el tema. En junio de ese año, se le encargó preparar una clase sobre qué es la arqueología experimental, cómo se hace y dónde en Europa. Con este propósito, se realizó una entrevista. Contactamos con 36 organizaciones e individuales, de los cuales 6 no eran miembros de EXARC, 23 respondieron (64\%). Estas respuestas deben ser consideradas anecdóticas por su bajo número. Las respuestas se dividían entre universidades (6 de 7 respondieron, 86\%), sociedades (9 de 15 
respondieron, 60\%), freelancers (4 de 7 respondieron, 57\%) y museos (4 de 7 respondieron, $57 \%$ ).

\section{Universidades}

Globalmente, hay más de un ciento de universidades ofreciendo educación en arqueología experimental; a veces esto incluye una semana inmersiva para aprender sobre la cultura material, en otros casos, hay completos doctorados producidos sobre el tema (EXARC 2018).

Algunas de las universidades con mayor trayectoria en arqueología experimental son la Universidad de Exeter (Reino Unido), Madrid (España) y la Universidad de Leiden (Holanda), otros han empezado recientemente como York (Reino Unido) y Vigo (España). La mayoría de ellos tienen una clara frontera en los temas que trata, como por ejemplo la tecnología de la Edad de Piedra / Prehistoria (Madrid, España), la cultura material de los cazadores-recolectores (York, Reino Unido) y la biografía de los artefactos (Leiden, Holanda).

EXARC cuenta con una lista de 100 universidades aproximadamente trabajando con la arqueología experimental. Cuando los departamentos de arqueología son grandes y el equipo es muy grande, algunos miembros suelen trabajar en arqueología experimental, la mayoría de los casos globalmente, y suelen depender de solamente uno o dos miembros del equipo, a menudo con la ayuda de estudiantes de postgrado.

Las universidades que se han incluido en esta investigación han integrado su arqueología experimental en una aproximación a largo plazo, con otros miembros del equipo del departamento de arqueología que han probado su experiencia en la arqueología experimental en algún momento de su investigación (comparar con Hurcombe, en: EXARC 2018).

A partir de la perspectiva de EXARC (EXARC 2018), la mayoría de las universidades utilizan la arqueología experimental como una herramienta para enseñar estudiantes de arqueología sobre arqueología, materiales y técnicas. El efecto indirecto es evidente: cuando un número limitado de estudiantes de máster y doctorado se centran complemente en los métodos de investigación de la arqueología experimental, un número superior de estudiantes acaban aplicado estos métodos en algún momento de su carrera futura.

Es menos común que los estudiantes apliquen arqueología experimental ellos mismos. Un motivo por el cual, los estudiantes producen muchos menos experimentos pequeños que son presentados en conferencias como REARC Conference en Estados Unidos (www.REARC.us). Los investigadores en las universidades a menudo trabajan en proyectos de investigación a largo plazo que conducen a menos publicaciones, pero planteando cuestiones más complejas. Aquí hay un claro efecto secundario que ocurre:

'La mayoría de mi enseñanza está centrada en la investigación así que les doy a los estudiantes proyectos que están derivados delpara mis propios intereses de investigación'

Little, University of York, Reino Unido (EXARC 2018).

La difusión pública y su impacto es la consideración final. Las universidades pueden ir fuera de su campus y formar parte en un museo u otros eventos públicos, que no solo es dar voz a su mensaje al público, sino también recibir inputs de parte de la audiencia. 
'Tenemos una aproximación muy académica e investigadora. No obstante, también reconocemos que el conocimiento adquirido a través de los modelos experimentales para la mejora del patrimonio histórico y antropológico es esencial. Además, nosotros creemos que la arqueología experimental es una herramienta básica para investigar y divulgar el condimento del pasado humano' Baena Preysler, Universidad de Madrid, España (EXARC 2018).

'La transferencia de ideas sobre los procesos que hemos experimentado como individuo, en una variedad de eventos (demostraciones públicas experimentales, talleres temáticos, conferencias especificas), han generado no solamente conversaciones interesantes, sino también han puesto a prueba las complementariedades entre los lenguajes de diferentes esferas: el lenguaje de arqueología a través de poner más atención al registro y la evidencia arqueológica; el lenguaje físico-químico de la arqueometría, mayor atención al fenómeno de la ciencia de los materiales; y finalmente al lenguaje artesanal que incluye el contacto humano con facetas materiales y experiencias que se deberían considerar como perspectivas vitales' Comendador Rey, Universidad de Vigo, España (EXARC 2018).

\section{Asociaciones}

Hay diversas asociaciones nacionales relacionadas con la arqueología experimental en Europa (por ejemplo, la VAEE en Holanda, Experimenta en España, EAS/AES en Suiza y EXAR en Alemania). En algunas universidades, hay una asociación estudiantil sobre arqueología experimental (por ejemplo, EXARN en Newcastle University, en Reino Unido, CEXA en la University of Zagreb en Croacia (ver Figura 1) y Harjis en la University of Łódź, Polonia). Finalmente, numerosas asociaciones de recreación histórica también incluyen la arqueología experimental en su perfil. Un gran número de grupos en la entrevista se debe a la división entre los grupos de arqueología experimental (6 de 6 contestaron) y grupos de recreación histórica (3 de 9 contestaron, 33\%). Pero, con el tiempo, estos dos grupos han ido apareciendo cada vez más. Las asociaciones ofrecen una oportunidad para sus miembros; les facilitan actividades, pero ellos no plantean las suyas propias. Sobre todo, son una plataforma para exhibir y cooperar con individuos con intereses similares. Los límites de tiempo y espacio se basan en los intereses de los miembros.

Para los individuos es también un hobby, investigación estudiantil, o un interés profesional. Estas asociaciones nacionales a menudo tienen opciones propias para publicar, aunque no acostumbran a llegar más allá que los propios miembros. Acostumbran a ser una vez al año, cuando los miembros se ven en persona. 


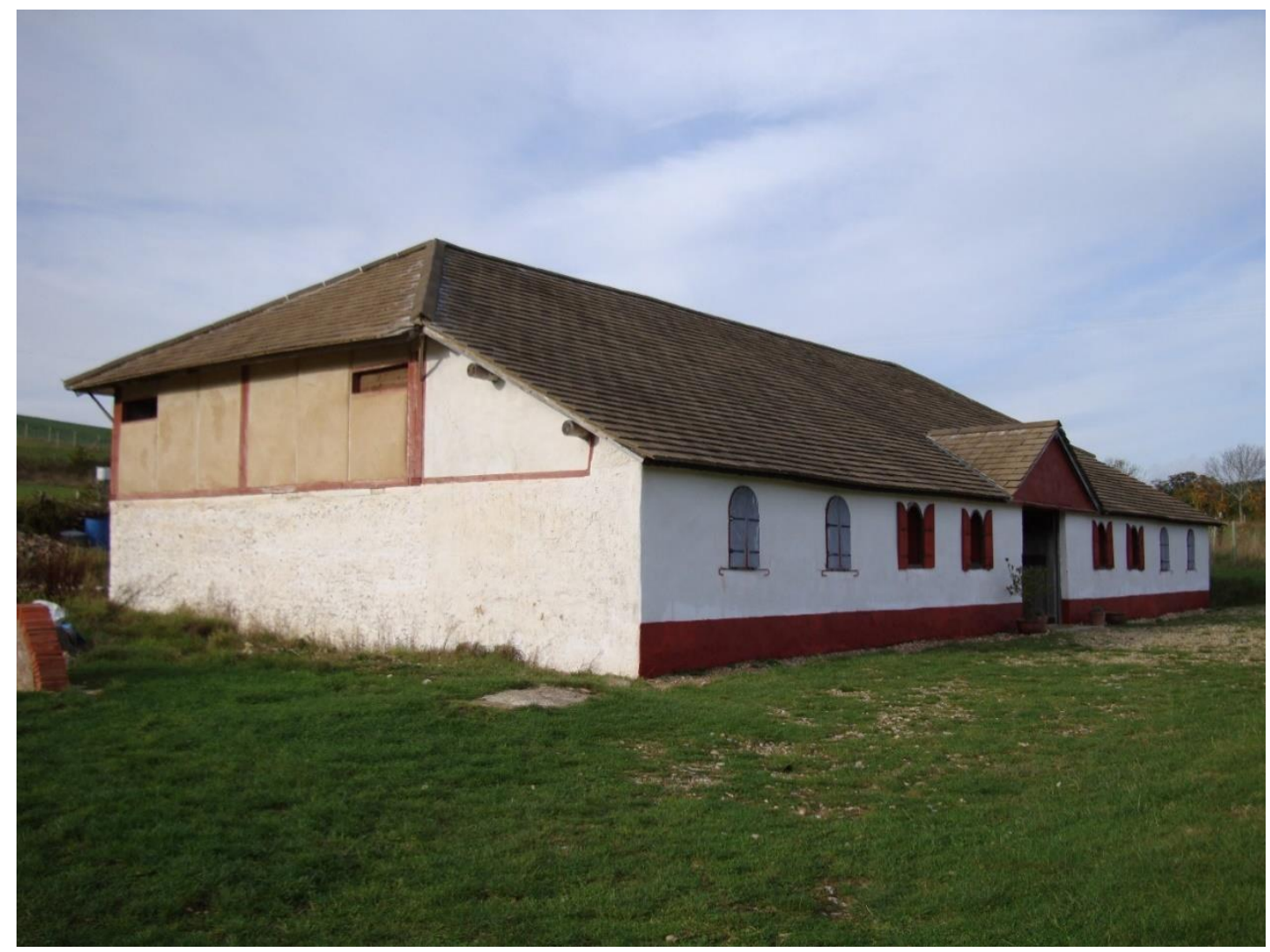

Figura 1- Butser Ancient Farm - UK

Las asociaciones de estudiantes también facilitan la investigación de sus miembros. A menudo son actividades aisladas, aunque estos procesos pueden tardar varios años y sus temas están bien definidos en tiempo y espacio. Los senior o estudiantes graduados suelen asistir con los nuevos; el contacto entre los miembros es más intenso que el que hay entre los miembros de las sociedades nacionales. Los resultados se presentan a menudo en conferencias de estudiantes, en el EAA o en conferencias EAC internacionales; la publicación depende de estas conferencias, así como trabajos de final de grado y de máster propios de los estudiantes.

Muchos miembros de las asociaciones de recreación histórica tienen intereses en replicar objetos, vestuarios y presentar actividades específicamente diseñadas en un periodo y ubicación concretos. Muchos grupos incluyen científicos, pero no todas las asociaciones son capaces de conducir una investigación adecuada. Un motivo para esto, es la disponibilidad limitada de recursos, así como la falta de capacidad crítica, y esto conduce a inexactitudes que son copiadas entre las asociaciones de recreación histórica. No obstante, el número de asociaciones de recreación histórica realizando investigaciones y experimentación está aumentando con el tiempo (Figura 2). 


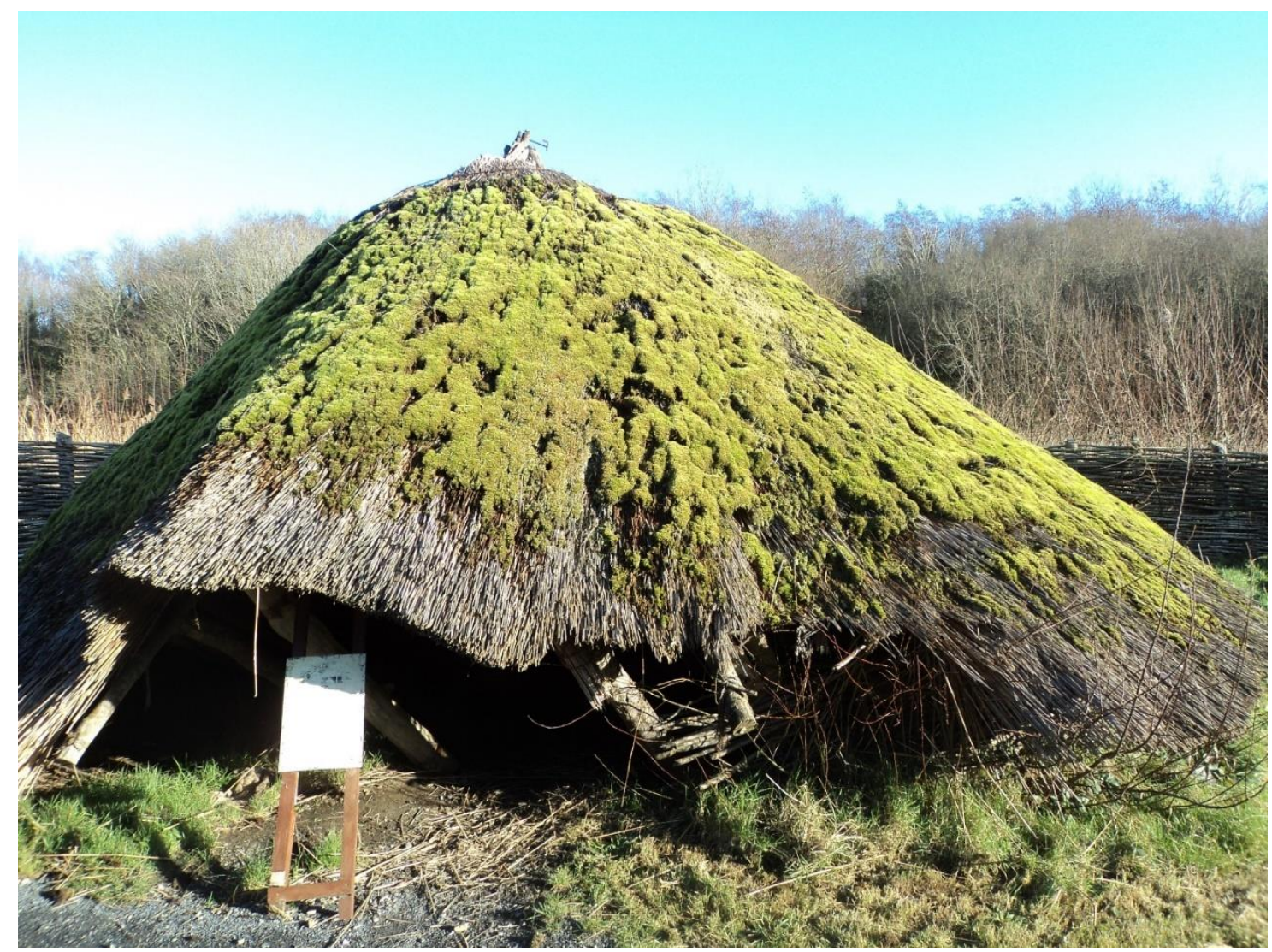

Figura 2 - Experimental archaeology research - Irish National Heritage Park - Ireland

Según la entrevista, muchos grupos tienen una buena idea sobre cómo la arqueología experimental se puede aplicar, tanto en largo y corto plazo.

'Es complementaria (a otros métodos arqueológicos) y una manera de enseñar al público sobre el pasado de una manera atractiva'.

Mariani, Popolo di Brig, Italia (EXARC 2018).

'Nosotros conducimos proyectos que únicamente tratan un pequeño aspecto de la arqueología experimental que es el estudio para la divulgación. Deberíamos entender la Arqueología Experimental cómo una disciplina real que, a través de experimentaciones, tiene éxito en formular hipótesis sobre objetos y acciones que, de otra forma, serían meros artefactos sin explicación'.

Salviati, Sippe Ulfsson, Italia (EXARC 2018).

\section{Freelancers}

Los freelancers en esta entrevista son autónomos y esperan cobrar por su trabajo como parte de su negocio. Para ellos no es un hobby, puesto que es parte de o completamente su profesión. Respuestas de Alemania, Grecia, Reino Unido y Suiza tienen una aproximación a largo plazo y un claro conocimiento de su tiempo y espacio. Su trabajo se basa mayoritariamente en satisfacer su propio interés, a menudo pagados por los museos que les piden que construyan o hagan demostraciones sobre algún tema. Algunos de ellos tienen experiencia en el mundo académico, otros en artesanías o autodidactas. Ellos saben que la buena reputación aumenta su valor en el mercado con los museos y universidades. Trabajan con arqueo-técnica (ver la explicación más abajo) así como con 
arqueología experimental. Se enorgullecen de hacer las cosas bien e invertir su tiempo en publicar en blogs o artículos.

\section{Museos}

También hay museos con un componente de investigación de arqueología experimental. Dado que hay limitaciones para desarrollar la investigación, tienen que definir sus proyectos de investigación de temas muy acotados, en tiempo y espacio; necesitan considerarla en un marco interpretativo del museo y ser directamente aplicables en la presentación del museo y sus eventos.

'Nuestras actividades en arqueología experimental están conectadas con cultura material romana y arquitectura, técnicas y herramientas de diferentes artesanías (...), sus resultados y técnicas a menudo están preparadas para presentar aspectos de la vida del pasado al público'-

Schwarz, Saalburgmuseum, Alemania (EXARC 2018).

La mayoría de los casi 100 museos miembros de EXARC cooperan con universidades cercanas. Esto les permite consolidar sus contactos con la Academia y seguir al día los desarrollos científicos. También les proveen de estudiantes a través de prácticas. Un efecto secundario en el aura de ciencia que se adhiere a la reputación del museo.

En un museo al aire libre, se pueden llevar a cabo actividades que no se podrían realizar en un espacio confinado. Además, estos museos están muy bien preparados para experimentos a largo plazo con un coste bajo. Un ejemplo es la experimentación con arcos para evaluar el deterioro en los arcos o en los huesos de animales.

También muy conocidos son los experimentos sobre procesos post-deposicionales donde ciertos artefactos son dispuestos de manera controlada y, más tarde, excavados. Finalmente, durante décadas, diversos museos (p.e. L'Esquerda en España, la Butser Ancient Farm en el Reino Unido y Százhalombatta en Hungría) han cultivado cereales, conocidos en la Prehistoria para conocer más sobre su cultivo.

\section{Qué es la arqueología experimental}

Se debe mencionar que el número de personas que utilizan la denominación arqueología experimental, así como el número de contextos en los que se usa, se está expandiendo rápidamente. Cuando se busca describir el campo de la arqueología experimental en todos los aspectos, está claro que tener una perspectiva completa es casi imposible. Me disculpo por no mencionar los aspectos de la arqueología experimental que están fuera de mi alcance y será bienvenido cualquier comentario, y así seguir con la discusión.

En el pasado la arqueología experimental estaba limitada a ejercicios puramente científicos con una clara hipótesis, proceso de trabajo y resultados ya ha pasado. Esto ha conducido a comentarios negativos y rechazos por parte de los arqueólogos. En mi opinión, la definición de arqueología experimental depende del contexto en que es utilizada. Por un lado, hay contextos académicos con una definición muy estricta del sentido de la investigación y de la educación estudiantil. También hay una segunda línea de trabajo en arqueología experimental, en el ámbito del turismo, que tiene un significado completamente diferente y que pocas personas consideran su valor científico. Algunas actividades experimentales, como los programas de la TV, se pueden describir mejor como experimentos sociales, donde la actividades pedagógicas tienen otra dimensión. Ninguna de estas visiones se puede considerar como la poseedora de la definición de la 
arqueología experimental. De hecho, es evidente que existe un valor añadido cuando las actividades académicas se incluyen en otras áreas y viceversa (Paardekooper, 2010).

Muchos participantes en la entrevista EXARC 2018 acordaron que la arqueología experimental está ampliamente aceptada e integrada como método de la ciencia arqueológica.

'Se está convirtiendo, cada vez de manera más integrada, en una aproximación arqueológica, como serían la bioarqueología, la zooarqueología o la imagen digital. Como resultado, la arqueología experimental está siguiendo una estructura científica más tradicional, con un énfasis más claro en hipótesis y teoría. Esto, para mí, es un cambio positivo y emocionante - resultando en una aproximación mucho más amplia e integrada en la investigación experimental con ciencias 'duras' y 'blandas' combinadas'. Little, Year Centre, University of York, Reino Unido (EXARC 2018).

'La arqueología experimental es uno de los campos que promete más en la Arqueología puesto que incluye nuevas maneras innovadoras y científicas para abordar la cultura material pasada. El experimento científico, como base de la arqueología experimental, aporta seriedad en la investigación de una manera que conecta mejor las ciencias naturales con las aproximaciones arqueológicas tradicionales. Kropp, Experimentalarchäologisches Freilichtlabor Lauresham, Germany (EXARC 2018).

Por otra parte, algunas personas enfatizan el poder sensorial, educacional y metodológico de la investigación en la aqueología experimental. La arqueología experimental es más fácil de usar como una herramienta para captar al público que para la investigación. Para muchos, su punto fuerte está en su capacidad para captar a la audiencia, haciendo la investigación relevante e interesante para una audiencia diversa.

'Cada generación de arqueólogos experimentales tiene que cometer los mismos errores, el mismo 'estatus de principiante', el mismo 'tener que tragarse las cosas antiguas' - y ¡la misma sonrisa orgullosa de finalmente haber tenido éxito!' Fasnacht, Suiza (EXARC 2018).

'La arqueología experimental ya no está limitada a solo algunos experimentos en arqueología, es sobre la Gente de Hoy, su fascinación por la arqueología, su interés en el pasado, isu captación en la investigación!'.

'El rol de la arqueología experimental en la investigación científica se basa en ubicar modelos que se han propuesto en la teoría en un lugar actual, con el objetivo de validar o modificar las premisas examinadas, así como explorar y obtener nuevas ideas; al mismo tiempo, ofrecen información significativa sobre el valor sensorial y la naturaleza de la técnica en los proyectos de investigación arqueológica'. Comendador Rey, Universidad de Vigo, España (EXARC 2018).

'Sin la interpretación y la interfase pública, con explicación, es simplemente un ejercicio académico, que no añade nada a la comprensión global del pasado colectivo’. Freeman, Reino Unido (EXARC 2018).

'En la universidad, es una herramienta de investigación avanzada en Arqueología pero en círculos más amplios, es una herramienta poderosa y fuerte para la educación y captación en muchos niveles'. Hurcombe, University of Exeter, Reino Unido (EXARC 2018). 
'La arqueología experimental es aún una manera práctica de obtener conocimiento sobre el pasado que no se puede adquirir de otra manera. Además, sus resultados y técnicas suelen estar adaptado para presentar aspectos de la vida pasada al público'. Schwarz, Saalburgmuseum, Alemania (EXARC 2018).

En diversos países se le ha dado más atención a la arqueología experimental y hay más gente que trabaja en ella que en otros. Contactos internacionales, también a través de las redes sociales, son de gran ayuda. No obstante, aumentar la presencialidad en conferencias y talleres es, sin duda, un elemento de gran interés para el avance de la arqueología experimental.

Una buena infraestructura internacional es necesaria, para facilitar los contactos e intercambio de recursos, mejores prácticas e información. Hay una necesidad de definir la ética en la arqueología experimental, así como la disponibilidad de manuales. Hay mucha información no publicada.

Mucha información experimental es adquirida, pero solo una fracción de este material se publica. La mayoría del material publicado aparece solo en la literatura gris. EXARC tomó la iniciativa de recolectar esta información a través de su Experimental Archaeology Collection, disponible en www.experimentalarchaeology.net. Empezó como una bibliografía online con 11.500 títulos en arqueología experimental y ahora es parte de tDAR, la Digital Archaeological Record. El sistema ahora incluye cualquier documento relacionado con la arqueología experimental y es una herramienta útil para cualquier tipo de investigación arqueológica experimental.

Empezando por el ámbito científico, creo que la arqueología experimental es una aproximación al registro arqueológico que empieza con una buena investigación de las fuentes primarias, seguido por el desarrollo de una hipótesis, explicando ciertos aspectos del registro arqueológico o de la gente responsable de este registro.

Para evaluar la hipótesis, es necesaria una acción, comparable a la acción arqueológica supesta. Para esto, un nivel correcto de experiencia es requerido, en artesanía, buen manejo del tiempo y del espacio de la arqueología original.

Esta acción deja huellas, produce información, de una manera documentada y que sirve para un propósito.

Esta información se compara con el registro arqueológico para comprender mejor la posible acción que tuvo lugar en el pasado. Una acción pasada es comparada con una acción presente de manera que, los dos tipos de información son contrastados. Es muy complicado controlar o describir la influencia de todos los factores en la acción.

La arqueología experimental es una herramienta versátil que conecta museos, universidades, sociedades y freelancers. También mantiene a todos ellos en contacto directo con la audiencia que le gusta ser sorprendida por el pasado y que sus preguntas tengan respuesta. En algunas partes de estas actividades cooperativas están. Bien estructuradas, el valor añadido es enorme.

La arqueología experimental no está limitada al mundo académico. Con algunas simples medidas, muchas acciones en la reconstrucción arqueológica, tecnología antigua, recreación histórica o educación y formación de los estudiantes, puede contribuir inmensamente a nuestro conocimiento del pasado: 
'Lo que hace la arqueología experimental es utilizar las habilidades tecnológicas primitivas, comprender el registro arqueológico y replicar esas herramientas y tecnologías para comprender mejor cómo se hicieron, cómo se utilizaron, cómo funcionaron, cómo de eficientes eran y, finalmente, cómo se descartaron y empezaron a formar parte del registro arqueológico'.

Schindler III, 2018.

Mucha gente está relacionada con la arqueología experimental, desde gente especializada, hasta aventureros. Gente con diferente formación participa y provee inputs incluyendo arqueólogos, estudiantes, artesanos y arqueo-técnicos. Profesores, tanto de escuelas o museos, también comparten su experiencia (Figura 3).

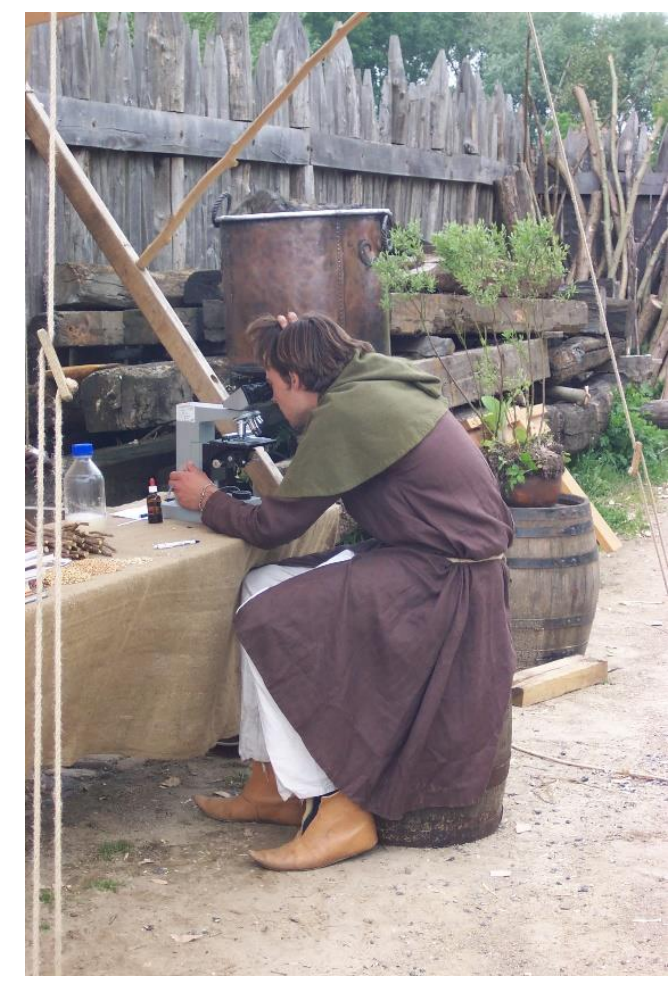

Figura 3 - Ancient Crafts \& Modern techniques - Prehistorisch Dorp - the Netherlands

El valor más grande emerge de la cooperación entre diferentes mundos de la arqueología experimental. A menudo, las diferentes entidades mencionadas previamente cooperan de diferentes maneras: actores de recreación histórica estudian arqueología, académicos trabajan a media jornada es museos, freelancers se unen a proyectos de arqueología experimental, etc. No obstante, aunque todos realizan proyectos de investigación a largo plazo, la cooperación con otras partes interesadas suele ser a corto plazo. La arqueología experimental forma parte de una estrategia amplia de investigación, educación y comunicación; frecuentemente es parte de otra cosa más grande. Es interdisciplinaria y relaciona la arqueología con el público.

\section{Ejemplos confusos}

Hay diversas actividades, relacionadas con la arqueología experimental que tienen importancia y que, a menudo conducen a experimentos bien fundados. Frecuentemente estos temas emergen cuando se discute la arqueología experimental en museos, conferencias y en la universidad. Es extremadamente difícil dibujar una línea entre lo que se incluye en la arqueología experimental y lo que no - mayoritariamente porque la 
arqueología experimental es un campo interdisciplinar, como se ha mencionado anteriormente, y se practica en varios contextos con diferentes propósitos y objetivos.

\section{Arqueo-técnica - Demostraciones de Tecnología Antigua}

Las demostraciones de tecnología antigua para los turistas se definen como arqueotécnica: alguien presenta las técnicas, por ejemplo, forja en bronce o talla de piedra a un grupo de personas. Se explica al público mediante su réplica las técnicas, los materiales y las herramientas utilizadas por una sociedad del pasado.(Hein, 2000). La arqueotécnica también incluye tecnología antigua o primitiva (este concepto es ampliamente utilizado en los Estados Unidos, por ejemplo, por parte de la Society of Primitive Technology). Es parte de la cultura de hacerlo uno mismo, donde antiguas las artesanías se cuidan para que no acaben desapareciendo. La arqueotécnica suele ser más que una mera demostración en museos; no es solo pulir las herramientas, sino también utilizarlas para algo útil. Los arqueotécnicos suelen ser artesanos hábiles con un buen conocimiento de los recursos arqueológicos.

Estas actividades son muy importantes, y muchos de estos especialistas también ejercen la arqueología experimental. No obstante, la arqueotécnica y la arqueología experimental son diferentes actividades, con diferentes propósitos y condiciones.

\section{Reconstrucciones}

Una sola reconstrucción no es un experimento. Los resultados (ropa, herramientas o una casa) sirven otros propósitos. Un experimento arqueológico conduce a obtener datos comparables con los arqueológicos. Llevar a cabo la construcción de casa a escala real o un modelo, especialmente en un museo arqueológico al aire libre es una actividad importante, dónde uno hace esfuerzos para contar una historia, pero para los propósitos de la arqueología experimental, estos son solo el subproducto, no el objetivo principal.

Reconstrucciones de, por ejemplo, ropa pueden ser de mucha calidad, a menudo mostrando la habilidad del artesano/a, tanto en las técnicas y materiales como en el conocimiento del registro arqueológico original. Esto puede ser un gran trabajo como material de exposición, o para una escena interpretativa en vivo, donde la persona vestida con esa ropa lo explica todo sobre la producción, el tiempo y el sitio, que evoca así como se utilizaba. No obstante, estas practicas no constituyen un experimento.

\section{Experimentos en vivo}

Los conocidos como campamentos de verano 'Back to Old Times' o los 'Experimentos en Vivo' pueden ser interesantes como shows de televisión y, en el caso que la prensa no esté relacionada, son momentos muy interesantes para que los individuos demuestren sus habilidades mientras forman parte de un experimento social. Dos buenos ejemplos de esto son 'Steinzeit das Experiment' (ARD/ZDF) y 'Seven in the Past' by Ratbor (http://ratobor.com/en/projects/seven-in-the-past/). Estos campamentos pueden conducir hacia una arqueología experimental en el sentido que la experiencia obtenida es un buen fundamento para experimentos estructurados, pero no se debe considerar como arqueología experimental. Coleccionar experiencias personales no es un experimento. Esto cuenta también como actividades pedagógicas donde los niños pueden hacer descubrimientos por ellos mismos. 


\section{Experimentos en arqueología}

Los experimentos científicos tienen que seguir una aproximación bien estructurada (c.f. Lammers-Keiisers, 2005). No obstante, solo una aproximación científica no es suficiente: uno necesita también un artesano con experiencia, que conozca suficientemente el estado de experiencia de la sociedad arqueológica en la que trabaja: el tiempo y el espacio restringen qué tipo de materiales se pueden usar y hasta qué nivel ciertas técnicas pueden ser introducidas o no.

\section{La construcción de una réplica de un barco vikingo en Roskilde - ¿por qué fue un experimento?}

La construcción de la réplica del barco vikingo Sea Stallion de Glendalough en Roskilde, (Dinamarca), y su viaje ida y vuelta a Irlanda en 2007 sirvió para diversos objetivos no solo científicos -turismo, nacionalismo, y nostalgia claramente jugaron un papel también. Fue demasiado caro para ser usado solamente como modelo científico. No obstante, un efecto aparte de la construcción de este barco y su navegación, fue que con esta reconstrucción o modelo, los arqueólogos, los constructores y el equipo fueron forzados a volver a la información arqueológica para responder cuestiones específicas que de otra manera nunca habrían surgido. Una pregunta a menudo conduce a docenas más.

\section{¿Cuándo se construyó la casa como experimento?}

Un ejemplo antiguo de la construcción de una casa inspirada por las evidencias arqueológicas es ,'Hans-Ole Hansen's Stone Age House' (Hansen, 1959). La mayoría de sus primeros trabajos se basan en ensayo y error,y en la experiencia continuada. La construcción de una casa es solo un experimento si implica la interpretación arqueológica (Comis, 2010, p. 10). La construcción, si se realiza en un museo al aire libre, se basa sobre todo en un escenario para actividades. No obstante, la caída de estas casas se puede monitorizar y más tarde ser excavadas y así podemos comparar las evidencias con los ejemplos arqueológicos (Rasmussen, 2007). En esos casos, se gana mucho con una simple documentación (Ver ejemplo en Figura 4, y más ejemplos de formas de documentación desarrolladas por J. Flamman; Flamman, n.d.). 


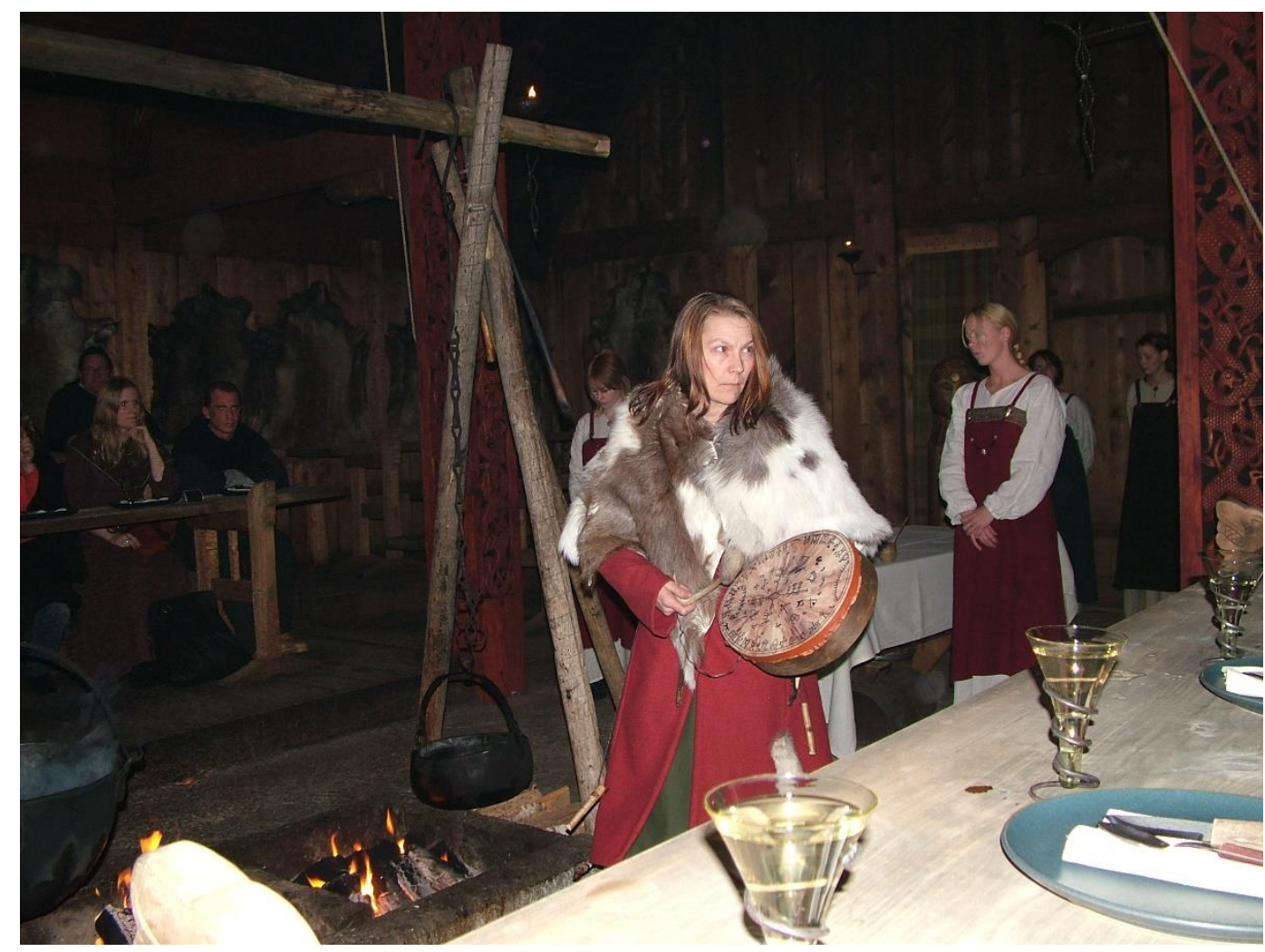

Figura 4 - Live interpretation - Lofotr - Norway

Desde el 1950, la experimentación ha producido mucha información para ayudar los arqueólogos a entender la arqueología. Se puede tomar el ejemplo de la arqueometalúrgia. Muchos artesanos, artistas y profesores la han relacionado en forma de experimentación; estas actividades han establecido un puente entre los arqueólogos, artistas y artesanos, a veces llevando a cabo una nueva investigación. La arqueología experimental se ha convertido en una herramienta importante en entender el pasado arqueológico. La arqueología experimental es atractiva y tiene mucho a ofrecer a los estudios arqueológicos convencionales, puede descifrar partes del pasado que no podríamos entender de otra manera. Utilizar la arqueología experimental aumenta nuestra estructura de referencia y además, nuestras hipótesis se convierten en más probables, nuestras analogías se convierten en menos ambiguas (Lammers-Keijsers, 2005, p.22).

\section{El futuro de la arqueología experimental}

Si tomamos una aproximación holística a la Arqueología, viéndola como ciencia de 'todo es humano' acorde lo que podemos aprender restos excavados e información, ¿no es sobre el tiempo que podemos ver o que podemos aprender sobre el pasado a través de la arqueología para nuestra sociedad presente? La arqueología no sería la primera ciencia en contribuir para mejorar nuestra vida actual y diversos compañeros se refieren a este escenario, por ejemplo, Holtorf: "la arqueología debería aceptar también aumentar los retos de la sociedad y las sociedades de futuras generaciones" (Holtorf, 2018, p.29, traducción rp), por ejemplo, "ayudando los refugiados desde zonas de guerras a procesar memorias traumáticas” (Holtorf, 2018, p.25, traducción rp).

¿Se puede hacer hormigón tan duro como el que hicieron los romanos? Algunos contratistas austriacos están actualmente investigando experimentos arqueológicos 
(Maier et al., 2018). ¿Son las formas de adquisición de comida, procesamiento y preservación de la Edad de Hierro la nueva tendencia porque son más sanas que lo que encontramos en el supermercado?

Los arqueólogos no pueden quedarse sentados en su torre de marfil; tienen que juzgar el impacto de su trabajo en la sociedad. No es sobre cómo de atractiva es la arqueología para el público, sino cómo de relevante es para solucionar los problemas modernos.

Así que, ¿cuál es la contribución de la arqueología a la sociedad moderna? Muchos problemas actuales también existieron en el pasado: desastres naturales, crisis económicas, integración cultural.

Debemos mirar qué clase de soluciones produjeron y aprendieron las sociedades antiguas que funcionaron o no en el pasado.

\section{Ejemplo: Calidad del aire en interior}

Hay cerca de 415 museos arqueológicos al aire libre solo en Europa que, de manera conjunta, tienen 19 millones de visitantes anuales. El número total de casas reconstruidas actualmente está cerca de 1,000. Un gran número de estas viviendas se utiliza para grupos educativos, Historia viva u otra clase de actividades. A menudo, el hogar está encendido varias horas al día, con gente dentro de la casa que, a veces, hasta duerme allí.

Hay grandes cuestiones sobre las condiciones de vivienda y la calidad del aire en el interior de estas estructuras. Esto no es solo importante para la gente que actualmente construye estas casas, sino que también es útil para entender situaciones similares en Asia, África y América del sur, acumulando datos sobre cómo de insalubre es esto.

Una cosa que se debe considerar en relación con estas casas es el uso moderno de estas habitaciones reconstruidas, especialmente cómo la gente manejó el fuego, haciendo referencia a la manera en que la gente manejó el fuego y el humo en cualquier otra parte del mundo.

Christiensen (2013a, 2013b) seleccionó dos casas de 'época vikinga' reconstruídas de manera similar y monitorizadas con las condiciones de vivienda que había dentro de las casas, durante 15 semanas en invierno. El objetivo del experimento fue examinar las condiciones interiores de las casas y compararlas con las de época vikinga cómo debieron afectar a sus habitantes. Las dos casas estaban habitadas y estaban hechas de zarza y quincha con techos de paja y un fuego en el centro de la casa. Tres de cinco participantes vivieron en las casas, pero tenían poca experiencia en cómo usar el hogar, reconstruir casas y/o en arqueología.

Los parámetros monitorizados durante el experimento fueron la calidad del aire (productos de combustión, pequeñas partículas, monóxido de carbono, dióxido de carbono y dióxido de nitrógeno), clima (temperatura y humedad relativa) y el índice de intercambio en el aire. También se registraron la luz, el consumo de la leña del hogar y su humedad, el uso de placas ajustables para el orificio del techo y las condiciones climáticas. 


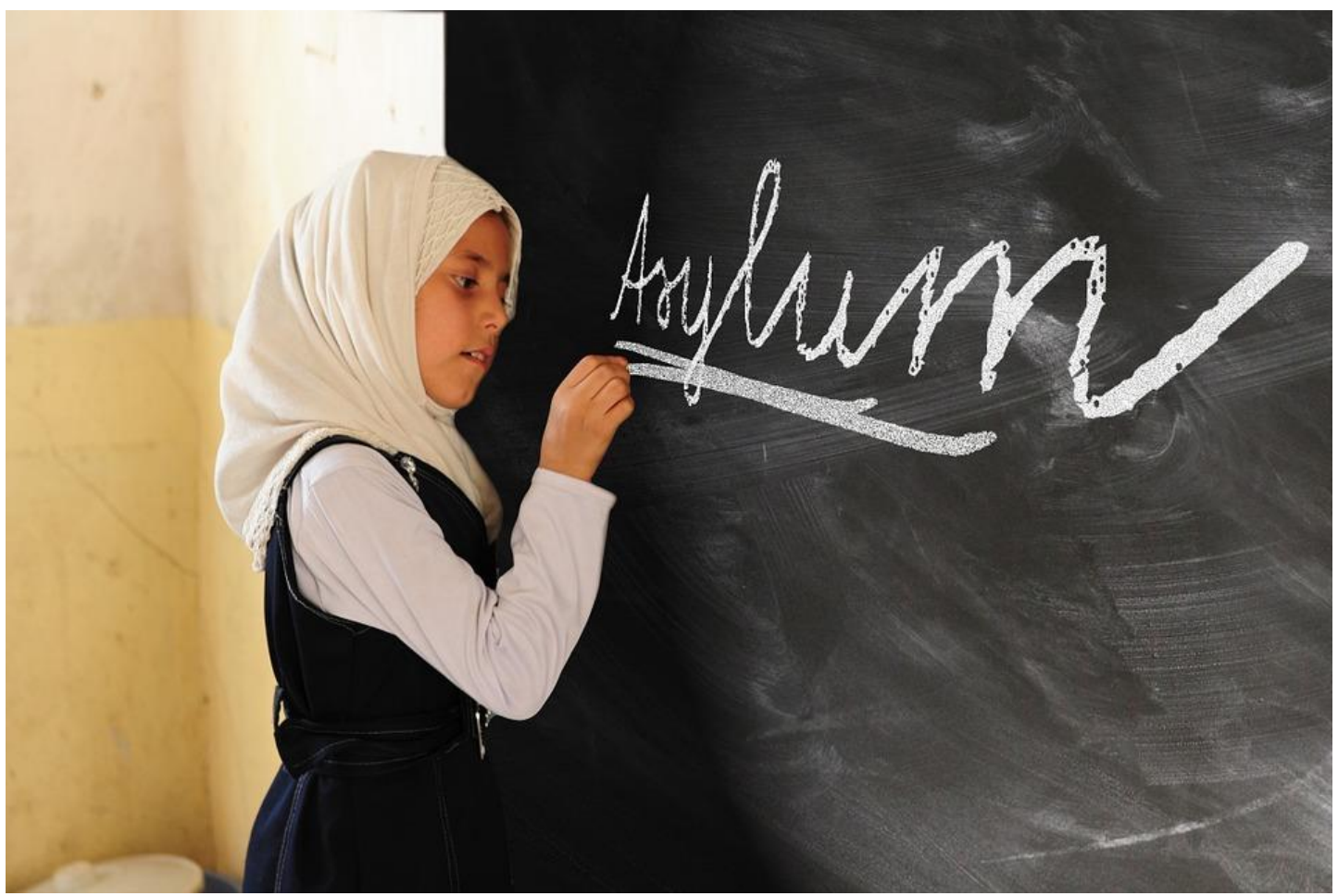

Figura 5 - Refugee girl in Germany (source https://www.maxpixel.net/photo-982119)

La World Health Organization (WHO) tiene directrices de la calidad del aire en interiores. Las concentraciones de partículas 24 horas y las concentraciones de dióxido de nitrógeno una hora dentro de las casas estaban fuera de las directrices de la WHO. La exposición a largo plazo al monóxido de carbono dentro de la casa estaba fuera de las directrices, aunque el riesgo de contaminación de monóxido de carbono en corto plazo era bajo. Las directrices respecto la exposición al monóxido de carbono nunca se excedieron.

En consecuencia, la presencia a largo plazo en casas reconstruidas con un hogar abierto no es bueno. El mayor riesgo para la salud proviene de las partículas finas (PM2.5) y del monóxido de carbono. No obstante, las casas suelen tener agujeros (demostrado por el cambio en el índice de aire de 10-15 por hora y la humedad relativa exactamente la misma que fuera de las casas), aunque es posible calentar el interior de las casas más o menos bien (sobre 10 grados por encima de la temperatura exterior).

Las concentraciones calculadas en las dos casas son comparables a casas similares de, por ejemplo, el sur de Asia o en la África subsahariana con un fuego o una estufa en la habitación principal (Lim, et al., 2012, pp.2247-2249). Aquí muchas mujeres y niños cogen infecciones respiratorias menores y problemas de riñones en casas donde se cocina y se calienta en fuegos con combustibles sólidos (Lim, et al., 2012, pp.2245). Actualmente, la exposición al humo de combustibles sólidos utilizados para cocinas y calentar en hogares abiertos en viviendas causa alrededor de 3.5 millones de muertes diarias en el mundo (Lima, et al., 2012, pp.2227-2251).

Los experimentos llevados a cabo en las casas vikingas confirman los datos recogidos a través de investigaciones etnográficas, con la diferencia de contar con medidas exactas y no únicamente anécdoticas.

\section{Ejemplo: Casas de césped}

Como parte de su investigación doctoral, en 2012 Postma construyó una casa hecha de césped, utilizando ideas de la Edad de Hierro y Edad Media del norte de Holanda. 
Investigó sobre información de construcción como la dureza del material, el valor de insolación, la permeabilidad del agua y la vida del producto. Aquí se sitúa el valor científico, económico y social que va más allá de la arqueología convencional.

El sector de la construcción rápidamente mostró un interés por las técnicas antiguas utilizadas por Postma. Es el caso del estudio de la Universidad de Eindhoven para una construcción sostenible. Vivir en este tipo de casas es un estilo de vida, donde uno mismo construye, construcción lenta y comunidades de construcción ecológica.

No obstante, Postma ve que algunos conceptos se utilizan más en maneras convencionales de construir. En la Universidad de Edinburgo, arqueólogos y arquitectos trabajan conjuntamente en cómo las técnicas de construcción antiguas y modernas, siguiendo siempre las regulaciones de seguridad, pueden inspirar las unas a las otras (Postma, 2015).

\section{Ejemplo: Flexibilidad de construcción en el Caribe}

Las islas de la región del Caribe a menudo experimentan condiciones naturales muy duras: hay una estación anual de huracanes (por ejemplo, los huracanes Irma y María en 2017) y, a veces, las islas sufren terremotos y erupciones volcánicas (Hofman y Hoogland, 2015). Sabemos que las comunidades del Caribe interactúan intensivamente entre ellas para compartir productos, ideas y técnicas a través del archipiélago (Hofman, Bridght y Rodríguez, 2010). Los arqueólogos han demostrado la presencia de técnicas comunes en estructuras en la región en el pasado, que todas juntas forman el "modo arquitectónico caribeño" (Samson, et al., 2015; NEXUS1492.eu, 2015). Las estructuras caribeñas pro-coloniales consistían primeramente en cimientos seguros y postes de soporte combinados con materiales ligeros, sugiriendo que esas casas habrían sobrevivido tanto a la tormenta como la reconstrucción rápida posterior(Samson, et al., 2015).

St. Vincent es una isla de las islas Windward del archipiélago caribeño. Aquí, un grupo de la Universidad de Leiden bajo la dirección de Corinne Hofman y Menno Hoogland excavaron un poblado del siglo XVI en 2009 y 2010. A partir de la configuración de agujeros de postes y las descripciones de los misioneros y viajeros del siglo XVII, el grupo, en colaboración con entidades locales, construyó una casa experimental (NEXUS1492.eu, 2016). Se construteron cuatro más rápidamente por los habitantes de St. Vicent. El pueblo es una contribución al patrimonio de la isla, documentando los habitantes más antiguos y es un caso extremadamente positivo de la cooperación para la preservación del patrimonio arqueológico (Hofman y Hoogland, 2016, pp.1516). En septiembre de 2016, esas casas sobrevivieron la tormenta tropical Matthew cuando pasó por la isla. La construcción era muy flexible y cuando fue necesario, las partes se podían cambiar fácilmente y reparar (Hofman, 2018). 


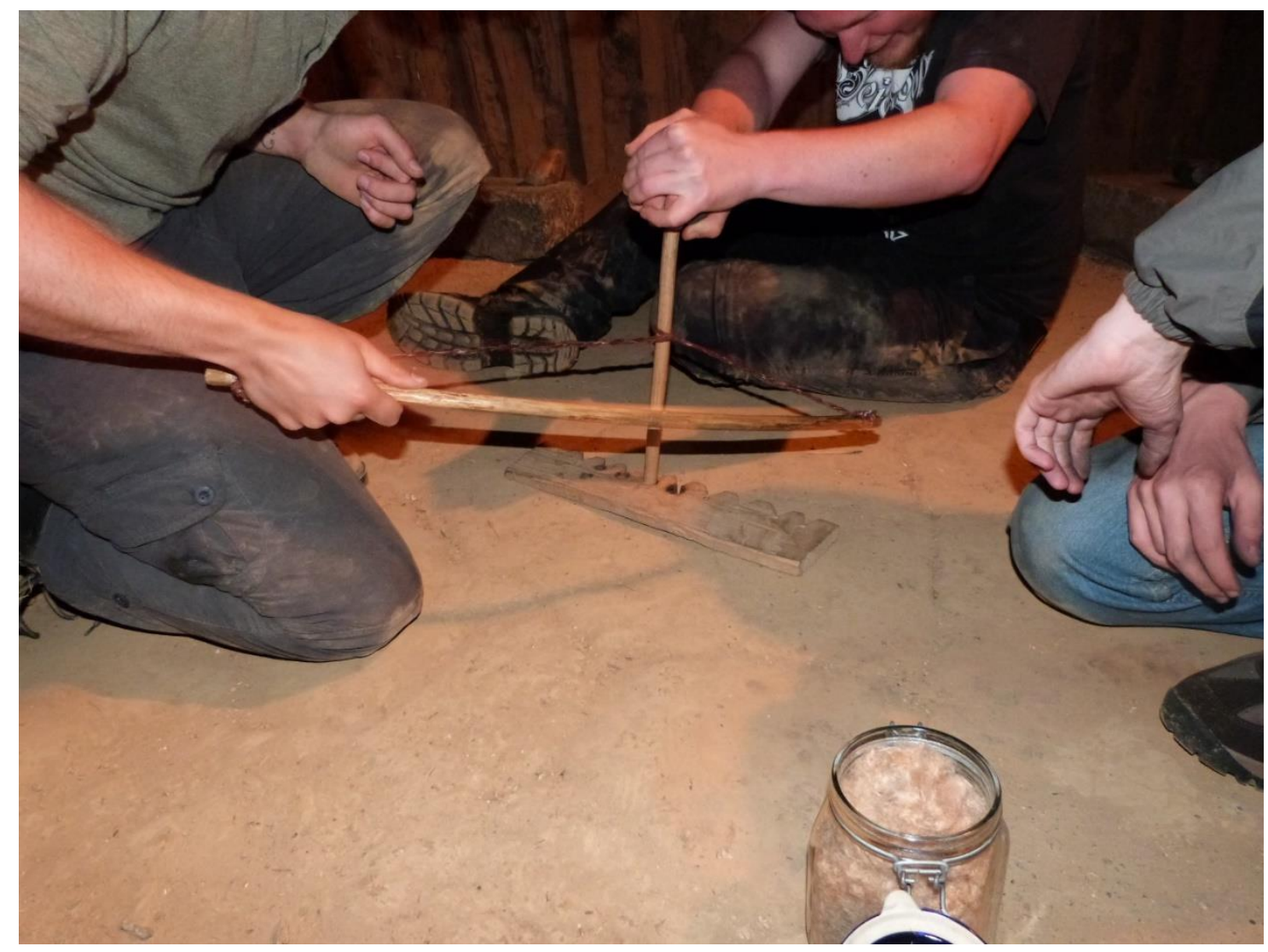

Figura 6 - Problem solving techniques -Cardiff students making fire at AFM Oerlinghausen, Germany.

La flexibilidad de las estructuras es una característica crítica de las casas precolombinas. Esta característica permitió que las casas se pudieran reconstruir y reemplazar algunas de sus partes. Estas características pueden servir como lección para la construcción en el clima impredecible caribeño, particularmente cuando organizaciones de ayuda humanitaria tienen muchos problemas para ofrecer un adecuado refugio (Samson, et al., 2015).

\section{Ejemplo: ¿Por qué deberíamos construir como los antiguos griegos?}

Muchos muros antiguos de todo el mundo (desde Grecia a Perú) parecen adoquinados al azar - aproximadamente ajustados con un espacio mínimo entre piedras adyacentes y sin uso de mortero. La construcción de muros de piedra seca es una técnica más sofisticada de construcción que lo que uno pensaría. Este estilo de construcción consiste en la utilización de piedras masivas de forma poligonal que encajan irregularmente pero de forma precisa, aunque tengan diferentes medidas y formas. Su ensamblaje es tan dramático que conjura mitos de los Cíclopes; un tipo de gigantes con un solo ojo, conocidos por construir muros de piedra que se llaman mampostería ciclópea. 


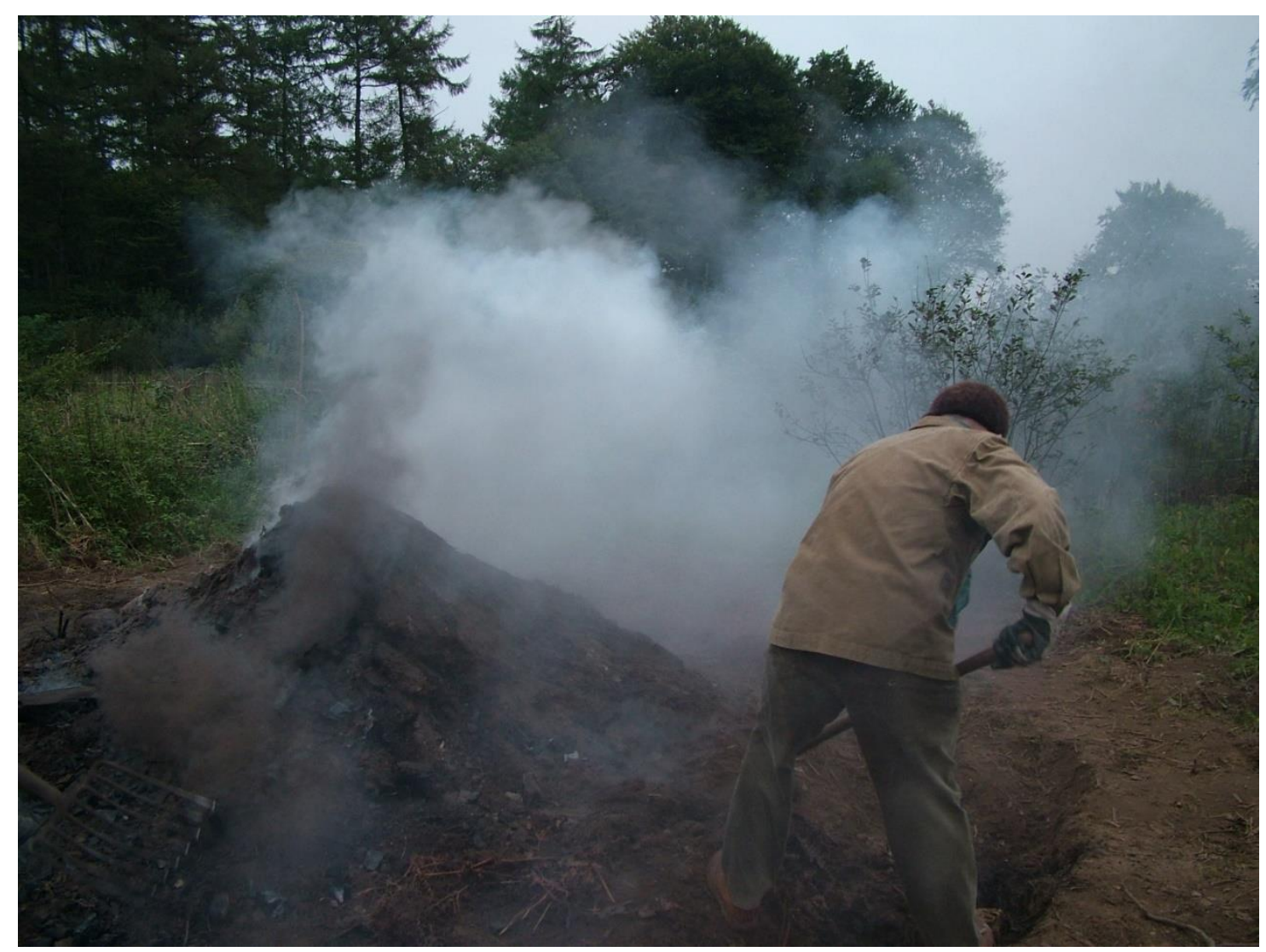

Figura 7 - producing charcoal can include important lessons for environmental education in the Stone Age Park Dithmarschen, Germany.

De las numerosas civilizaciones que produjeron trabajos de piedra megalítica, los Inma construyeron sin un diseño precedente. La arquitectura emergió a través de una secuencia lógica marcada por la falta de recursos. Cuando los materiales eran escasos, las piedras eran re-adaptadas en nuevos trabajos. Muchos de los materiales de construcción eran reutilizados: ruinas antiguas o construcciones en desuso se desmontaban y la gente reutilizaba estos materiales para construir nuevas estructuras. Estos muros parecían aleatorios e ilógicos. No obstante, la aleatoriedad es un derivado de una manera muy inteligente de reciclar edificios previos. De hecho, gente "canibalizaba" antiguos edificios, consumiendo sus ciudades.

En el contexto urbano de hoy, generamos cantidades de residuos sin precedentes. La industria de la construcción es una de las industrias que genera más residuos. En los Estados Unidos, 534 millones de toneladas de residuos de construcción son enviadas cada año a vertederos (USEPA, 2014), más del doble de la cantidad de residuos generada mundialmente. Hay una crisis en decidir qué hacer con los residuos de la industria de la construcción.

Para reconsiderar de manera más inteligente la existencia de stock de construcción, tenemos que aprender de los constructores ciclópeos. Estos métodos de construcción nos fuerzan a renunciar a los diseños de composición predeterminada a cambio de unas condiciones de diseño inteligente, capaces de responder a condiciones desconocidas.

El professor Clifford (Massachusetts Institute of Technology) investiga los métodos antiguos de construcción y los traduce a un contexto moderno. Experimentó con $1.000 \mathrm{k}$ 
de piedras en el agua, demostrando el concepto de transporte de las piedras de Stonehenge y replicando la física utilizada para crear las esculturas de piedra de la Isla de Pascua.

Cuando Clifford investigó “canibalismo ciclópeo" (2017), descifró la antigua técnica de construcción para medir las geometrías exactas de los muros ciclópeos por todo el mundo y después modeló cómo las piedras encajaban mejor. Puso toda esta información en un grupo algorítmico.

Los ocho diferentes algoritmos de Clifford pueden calcular la medida de las piedras y escombro que puede haber y, después, sugiere el tipo de diseño de muro ciclópeo que podría transformar los restos en un muro.

Para demostrar este concepto, una empresa de arquitectura de piedra seleccionó rocas de su pila de restos, así como algunos escombros de un lugar de demolición local, y después los escanearon utilizando el algoritmo de Clifford. Después, eligieron los resultados y construyeron un muro. Se completó en menos de una semana. Claramente, no todo tenía unos patrones perfectos - un recordatorio de que fueron los humanos quienes construyeron estos muros, no máquinas.

Las ciudades futuras necesitan una "canibalización" creativa de la acumulación de restos y estancadas estructuras. ¿Podemos urbanizar el futuro cercano re-imaginando una arquitectura autosuficiente? ¿Pueden las ciudades futuras digerirse ellas mismas? El "canibalismo ciclópeo" contribuye a una conversación más larga sobre sostenibilidad en la manera en que construimos. La arqueología experimental demuestra la posibilidad de aplicar este concepto a los problemas modernos. Esto es un ejemplo de ingenieros buscando solucionar un problema moderno, encontrando inspiración con los recursos arqueológicos.

\section{Ejemplo: Experimentos con los métodos de excavación de sepultura}

En su libro: Forensic Archaeology, el Dr Evis, de la University of Exeter, incluye tests experimentales presentes en las actuales técnicas de excavación arqueológica y de registro para validar la idoneidad para utilizarlas en el campo forense (Evis, 2016).

Cuando se excava, no todos los artefactos y su información se recupera, pero ¿de cuánta información estamos hablando exactamente? Un famoso ejemplo que presenta estas cuestiones, el Overton Down Experimental Earthwork, un talud experimental que fue construido en 1060 y fue excavado lentamente, cada vez en intervalos de tiempo más largos (Bell, et al., 1998). Esto parece un buen ejercicio arqueológico, pero no es solo importante para la Arqueología, dado que también considera qué pasaría si las evidencias recuperadas es utilizado en los tribunales. ¿Cósmo puede un juez decidir lo que la presencia o ausencia de ciertos aspectos significa en un contexto de sepultura, si no hay un experimento controlado en el que depender, analizado por arqueólogos forenses profesionales?

Cuatro arqueólogos experimentados habían excavado cada uno dos tipos de construcciones similares experimentales de 'sepulturas individuales' utilizando dos métodos de excavación diferentes: el método de excavación de nivel es arbitrario y el método de excavación estratigráfico. Los resultados de las excavaciones fueron utilizados para comparar índices de recuperación de forma variable de las evidencias ubicadas en las sepulturas. 
El método de excavación por niveles arbitrarios es el método estándar de excavación en excavaciones forenses (Komar y Buikstra, 2008). Durante la excavación por niveles arbitrarios de la sepultura, primero se estima la medida de la sepultura, seguido por la retirada de la tierra en capas predeterminadas. Cuando se identifica la evidencia, la tierra de alrededor se retira dejando cada elemento sobre un 'pedestal' de tierra. Estos elementos solo se retiran cuando están bloqueando el proceso de excavación (Connor, 2007). Este método ignora la presencia de diferencias en la estratigrafía. El énfasis principal en utilizar este método es sobre todo para recuperar los artefactos y los restos humanos, más que en comprender el proceso de formación de la sepultura.

Cuando se excava utilizando el método de excavación estratigráfica, se trabaja en contextos estratigráficos arqueológicos diferenciados. Estos se registran y se excavan como fenómenos estratigráficos individuales. El total de la sepultura se considera como un elemento arqueológico (Evis, et al., 2016). Las ventajas de este método incluyen el análisis y el registro de cada contexto estratigráfico y la identificación de las interfaces entre depósitos. Los problemas principales de este método es que es complicado, lento, y requiere arqueólogos con más experiencia en la realización de este trabajo.

Los experimentos demostraron que la excavación con el método estratigráfico tenía como resultado un índice más alto en el descubrimiento de todo tipo de evidencias, con una media del $71 \%$ de la evidencia descubierta. En cambio el método de excavación por niveles arbitrarios identificaba una media del 56\%.

Estos descubrimientos presentan cuestiones sobre la fiabilidad y la adecuación de estas técnicas de excavación que están establecidas y su uso ante un jurado.
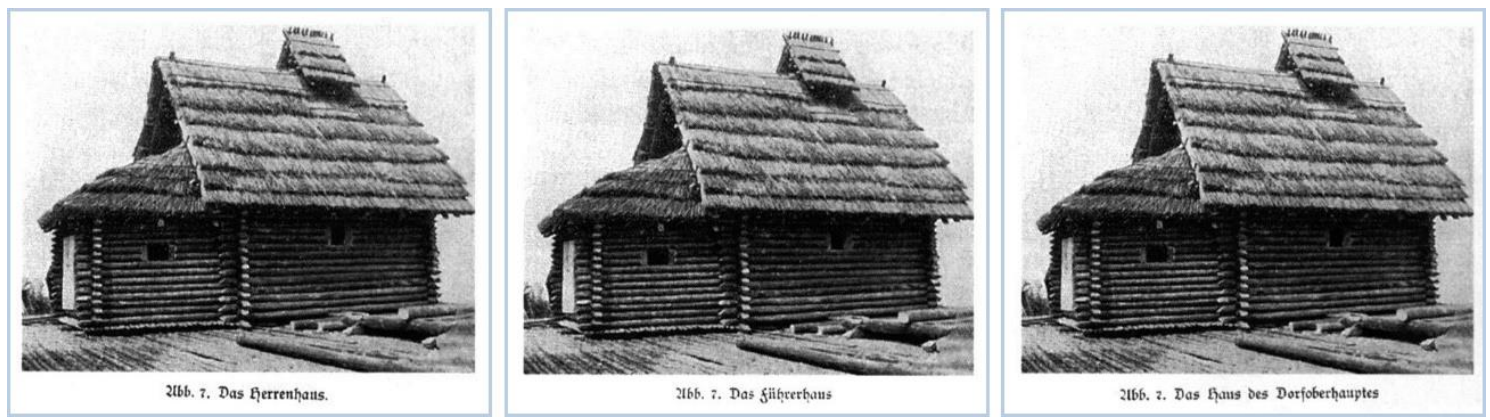

Figura 8 - (Re)construction of house 16 of the Wasserburg Buchau at the Pfahlbaumuseum in Germany and its description in the museum guide books (1st print 1931: 'the leader's house', 3rd print 1938: 'the Führer's house', 9th print 1951: 'the house of the village chief ') (source: Schöbel 2001, 55). 


\section{Conclusión}

Cuando se preguntó a los miembros de EXARC, universidades, sociedades, museos y freelancers, se identificó claramente que la mayoría de la investigación en arqueología experimental aún se hace sin ningún soporte estructural, por individuos que la realizan como una actividad secundaria, aparte de su trabajo principal. La arqueología experimental no solamente combina ciencias 'duras' con 'blandas', tal y como menciona Little en la entrevista del 2018 (EXARC 2018), también es un punto de unión entre científicos, artesanos, educadores y artistas con intereses similares.

Muchos miembros de EXARC están bien versados en el tema. Son profesionales y honestos sobre lo que hacen: investigación, educación y divulgación pública son muy importantes si se estructuran bien y se pueden ejecutar en la misma actividad.

Los buenos experimentos a menudo cumplen más objetivos que los marcados en la agenda científica. En parte, esto de debe a los costes elevados. Un experimento bien estructurado, con buena documentación y publicación es muy relevante para mostrar la arqueología experimental al público. La arqueología experimental se ha convertido en una herramienta importante para ayudar en la comprensión del pasado arqueológico. Gracias a la cantidad elevada de experimentos, nos estamos acercando en la comprensión de cómo la vida habría sido en el pasado.

Los ejemplos mencionados anteriormente sobre la aplicación de la arqueología experimental al mundo moderno nos han enseñado diversas cosas. Los museos arqueológicos al aire libre son buenos sitios para monitorizar experimentos, ofreciendo una base sólida que se puede combinar con los datos etnográficos. Hay muchas variables con las que se puede experimentar e intentar aplicar en la arqueología y en la sociedad actual. También es posible recoger información a gran escala sobre la construcción y la gestión de casas reconstruidas que, a la vez, nos informará más sobre los métodos constructivos con madera utilizados por todo el mundo.

Los arqueólogos necesitan aplicar un enfoque interdisciplinar en este área de la investigación: algunos de los mejores arqueólogos experimentales son ingenieros o artesanos, cooperando conjuntamente con arqueólogos. La arqueología forense es un campo importante que nos enseña que no podemos ver la arqueología como un campo separado que el mundo que nos rodea.

La arqueología tiene un rol cada vez más importante en el desarrollo de la sociedad a través de actividades públicas (Boom, 2018). Si los arqueólogos experimentales pueden incluir un elemento en ser relevantes para la comunidad moderna por su tipo de estudio, pueden, no solo atraer más financiación, sino también su enfoque científico, útil tanto para la ciencia arqueológica y la sociedad moderna. Nos tenemos que asegurar, no obstante, de que las buenas ideas desarrolladas en la arqueología se filtran en la sociedad moderna. 


\section{Agradecimientos}

Agradezco mucho a todas las personas entrevistadas por su cooperación. Muchas gracias al Prof. Dr. Hofman por comentar en gran detalle conmigo el ejemplo de (re)construcción de la casa de St Vincent.

\section{Bibliografía}

Schöbel, G., 2001. Die Pfahlbauten von Unteruhldingen, Die Pfahlbauten von Unteruhldingen, Museumsgeschichte. Unteruhldingen: Pfahlbaumuseum.

Bell, M., Fowler, P.J. and Hillson, S.W., 1998. Earthworks revisited, Antiquity. 72, pp.485-504.

Boom, K., 2018. Imprint of Action, Leiden: Sidestone.

Christensen, J.M., 2013A. Living Conditions and Indoor Air Quality in a Reconstructed Viking House, EXARC Journal. 2013(3). Leiden: EXARC [online] Available at http://exarc.net/issue-2013-3/ea/living-conditions-and-indoor-air-quali... [Accessed 23 September 2018].

Christensen, J.M., 2013B. Mennesket og huset - levevilkår og eksperimentelarkæologiske undersøgelser af indeklima i et rekonstrueret, Master Thesis in Archaeology, Aarhus University, pp.1-270.

Clifford, B., Addison J., Marshall D. and Muhonen M. 2017. The Cannibal's Cookbook: Mining Myths of Cyclopean Constructions, Matterdesign.

Coles, J.M., 1979. Experimental Archaeology, London: Academic Press.

Comis, L., 2010. Experimental Archaeology: methodology and new perspectives in Archaeological Open Air Museums. euroREA. Journal for (Re)construction and Experiment in Archaeology. 7/2010, pp.9-12.

Connor, M., 2007. Forensic Methods Excavation for the Archaeologist and Investigator. Lanham: AltaMira Press.

Evis, L., 2016. Forensic Archaeology: The Application of Comparative Excavation Methods and Recording Systems. Oxford: Archaeopress Archaeology.

Evis, L., Hanson, I and Nicholas Cheetham, P., 2016. An experimental study of two grave excavation methods: Arbitrary Level Excavation and Stratigraphic Excavation, STAR: Science \& Technology of Archaeological Research, 2:2: pp.177-191.

EXARC 2010. (unpublished) Results of the Survey, [survey conducted 2010] Leiden: EXARC.

EXARC 2018. (unpublished) List of universities working with experimental archaeology, [survey conducted 2018] Leiden: EXARC.

EXARC, Experimental Archaeology Collection, [online] Available at: < https://www.experimentalarchaeology.net > [Accessed 23 September 2018].

Flamman, J.P., n.d. Form to describe archaeological true to scale architectural models or (re)constructions. [unpublished document].

Hansen, H.-O., 1959. I built a Stone Age House, New York: The John Day Company. 
Hein, W., 2000. „Es recht zu machen jedermann...“ Archäo-Technik zwischen Authentizität und Machbarkeit. In: R. KELM, ed. Vom Pfostenloch zum Steinzeithaus. Albersdorfer Forschungen zur Archäologie und Umweltgeschichte. Albersdorf, pp.177-185.

Hofman, C.L., 2018. reconstructies op St Vincent. [e-mail] (Personal communication, 19 December 2018).

Hofman, C.L. and Hoogland, M.L.P., 2015. Beautiful tropical islands in the Caribbean Sea. Human responses to floods and droughts and the indigenous archaeological heritage of the Caribbean. In: W.J.H. Willems and H. Schaik, eds. Water and heritage: Material, conceptual and spiritual connections. Leiden: Sidestone Press, pp.99-119.

Hofman, C.L. and Hoogland, M.L.P., 2016. Connecting Stakeholders: Collaborative preventive archaeology projects at sites affected by natural and/or human impacts, Caribbean Connections 5(1), pp.1-31.

Hofman, C.L., Bright, A.J. and Rodríguez Ramos, R., 2010. Crossing the Caribbean Sea. Towards a holistic view of pre-colonial mobility and exchange. Journal of Caribbean Archaeology (Special Publication Number 3), pp.1-18.

Holtorf, C., 2018. Was hat Archäologie mit mir zu tun? Eine Archäologie der Zukunft, AS. Archäologie Schweiz 41.2018.3, Basel: Archäologie Schweiz, pp.24-29.

Komar, D., and Buikstra, J.E., 2008. Forensic Anthropology: Contemporary Theory and Practice. New York: Oxford University Press.

Lammers-Keijsers, Y.M.J., 2005. Scientific experiments: a possibility? Presenting a cyclical script for experiments in archaeology. euroREA: (Re)construction and Experiment in Archaeology - European Platform. 2/2005, pp.18-24, [online] Available at <https://exarc.net/sites/default/files/exarc-eurorea_2_2005scientific_experiments_a_possibility.pdf> [Accessed 23 September 2018].

Lim, S.S. et al., 2012. A comparative risk assessment of burden of disease and injury attributable to 67 risk factors and risk factor clusters in 21 regions, 1990-2012: a systematic analysis for the Global Burden of Disease Study 2010, vol. 380, December 2012, pp.2224-2260, [online] Available at < https://www.thelancet.com > [Accessed 23 September 2018].

Maier, K., Draxl, D., Leismuller, M., Muigg, M., Hanser, A. and Hortner, O., 2018. Rezepturentwicklung von Opus Caementitium zur Verwendung in Hypokaustheizungen. In: G. Schobel, U. Weller, T. Lessig-Weller and E. Hanning, eds. Experimentelle Archäologie in Europa, Jahrbuch 2018, Unteruhldingen: EXARC, pp.50-58.

Mathieu, J.R., 2002. Experimental archaeology, replicating past objects, behaviors and processes. Oxford: BAR International Series.

NEXUS1492.eu, 2015. Rebuilding after natural disasters: lessons from the preColumbian era. Available at: < https://www.universiteitleiden.nl/nexus1492/news/rebuilding-after-natur... > [Accessed 23 September 2018]. 
NEXUS1492.eu, 2016. Start of reconstruction indigenous village in St. Vincent. Available at: < https://www.universiteitleiden.nl/nexus1492/news/start-ofreconstructio... > [Accessed 23 September 2018].

Paardekooper, R.P., 2010. Performance in Experimental Archaeology, any Possibility for Unambiguous Statements? In: T. Kerig and A. Zimmermann eds. Economic archaeology: from structure to performance: pp.264-272.

Paardekooper, R.P., 2013. Experimental Archaeology and the International Perspective, the future of EXARC. In: M.C. Belarte, C. Masriera Esquerra, R. Paardekooper and M.J. Santacana eds. Espais de presentació del patrimoni arqueològic: la reconstrucció in situ a debat, Interpretation spaces for archaeological heritage: discussions about in situ reconstructions, Barcelona: Universitat de Barcelona: pp.83-88.

Postma, D., 2015. Het Zodenhuis van Firdgum, Groningen: Rijksuniversiteit Groningen, GIA, pp.307-315.

Rasmussen, M. ed., 2007. Iron Age Houses in Flames. Testing house reconstructions at Lejre, Lejre: Historical-Archaeological Experimental Centre.

RATOBOR, Seven in the Past, [online] Available at: <http://ratobor.com/en/projects/seven-in-the-past/\&gt; [Accessed 23 September 2018].

REARC, Annual Conference on Reconstruction and Experiment in Archaeology, [online] Available at: https://exarc.net/rearc [Accessed 23 September 2018].

Samson, A.V.M, Crawford, C.A., Hoogland, M.L.P. and Hofman, C.L., 2015. Resilience in Pre-Columbian Caribbean House-Building: Dialogue Between Archaeology and Humanitarian Shelter, Human Ecology, 43(2), pp.323-337.

Schindler III, W., 2018. in: Peak Human - A Food Lies Film Podcast by Brian Sanders, Part 17, [podcast] 26 September 2018. Available at < https://itunes.apple.com/us/podcast/peak-human-a-food-lies-film-podcast... > [Accessed 2 October 2018]

Staeves, I., 2016. An Energy Saving House from 3400 Years Ago, EXARC Journal, [online] Available at < https://exarc.net/issue-2016-3/aoam/energy-saving-house3400-years-ago > [Accessed: 23 September 2018].

United States Environmental Protection Agency (USEPA), 2014. Sustainable Management of Construction and Demolition Materials, $<$ https://www.epa.gov/smm/sustainable-management-construction-anddemolit... > [Accessed: 23 September 2018]. 